\title{
A Collective Case Study of African American Male Athletic Directors' Leadership Approaches to Diversity in College Sport
}

\author{
John N. Singer and George B. Cunningham \\ Texas A\&M University
}

\begin{abstract}
The primary purpose of this research was to garner an understanding of how African American male athletic directors manage diversity and inclusion in their college athletic departments. The authors conducted a collective qualitative case study of two major university athletic departments that each had an African American male athletic director. The authors conducted interviews, took field notes, and analyzed relevant documents/artifacts, all of which served as data sources. Results indicate these leaders viewed diversity and inclusion as (a) increasing racial and gender minority representation in leadership positions and (b) utilizing this diversity as a mechanism for role modeling and mentoring. Differences between the leaders also emerged, as one explicitly focused on conducting an organizational analysis and on making diversity training mandatory for all employees, while the other did not engage in these activities. The authors discuss contributions to the literature and future directions for research.
\end{abstract}

Keywords: race, gender, role modeling, mentorship, organizational analysis, diversity training

African Americans constitute a sizeable portion of all National Collegiate Athletic Association (NCAA) ${ }^{1}$ athletes, but are comparatively under-represented in leadership roles, particularly at predominantly White institutions of higher education (PWIHE). Consider the following data for the 2016-2017 academic year (National Collegiate Athletic Association, n.d.): African Americans constituted $31 \%$ of all women's basketball players, $38.7 \%$ of football players, and, more specifically, $44.2 \%$ of football players across all Division I programs (Lapchick, 2018). Despite these impressive figures, African Americans represented just $15.2 \%$ and $11.3 \%$ of the head coaches in those sports, respectively. The figures were even lower for athletic directors (ADs), where African Americans held just 20 of the

Singer and Cunningham are with the Laboratory for Diversity in Sport in the Department of Health and Kinesiology, Texas A\&M University, College Station, TX. Address author correspondence to John N. Singer at singerjn@tamu.edu. 
1,134 jobs during that year (1.7\%). These data are for all intercollegiate athletic programs and when removing Historically Black Colleges and Universities (HBCU) from the data, the trends are more dire. Though we offer statistics for the most recent data available, these figures have persisted over time. For decades, authors have shown that African Americans have more opportunities on the field and court than they do as coaches, administrators, or in other leadership roles (Anderson, 1993; Brooks \& Althouse, 2000; Lapchick, 2018). As Cunningham (2015) has outlined, these disparities largely stem from systemic racism in the college sport context, personal biases among decision makers, and discrimination, among other factors (see also Bimper \& Harrison, 2017; Corbett \& Tabron, 2007; Cunningham \& Sagas, 2005).

The lack of African Americans in leadership roles within intercollegiate athletics brings to bear the salience of diversity in this context. Diversity represents the presence of socially meaningful differences between and among people as they interact in various organizations and social contexts (Cunningham, 2015). Although race and gender have long been and continue to be the focal point of much of the literature on diversity in (sport) organizations, it is important to note that scholars have also discussed other forms of diversity, such as age, mental and physical ability, appearance, religion, sexual orientation and gender identity, and social class (see Cunningham, 2015). Moreover, some of the early work on diversity by sport management scholars advanced conceptual frameworks to understand diversity and its effects in the workplace (DeSensi, 1995; Doherty \& Chelladurai, 1999; Fink \& Pastore, 1999). More recently, authors have focused their attention on close examination of diversity programs (Rich \& Giles, 2015; Spracklen, Hylton, \& Long, 2006) and organizational efforts to promote diverse and inclusive environments (Cunningham, 2009; Spaaij et al., 2014). As Spaaij et al. (2014) observed, many sport organizations have moved from a focus on diversity as a social good to one where diversity is seen as a business case. This emphasis is consistent with theorizing (Fink \& Pastore, 1999) and subsequent work showing that leaders anticipate performance gains to result from a diverse and inclusive workplace (Cunningham, 2008b; see also Cunningham \& Singer, 2011). Interestingly, within the sport domain, White men have historically and continue to shape narratives around diversity and inclusion. That is, because White men are overrepresented in leadership positions (Cunningham, 2015), and leaders are frequently the primary drivers of diversity within organizations (Chemers \& Murphy, 1995), it is White men who have traditionally held the keys to the diversity car.

Our specific concern in this article was to offer another vantage point in the leadership and diversity discussion within sport. Specifically, we focus on how African American male ADs as diverse leaders think about and approach diversity efforts in their college athletic departments. We move beyond the typical focus on "issues of access or to counting the number of women or members of racial and ethnic minority groups in leadership positions" (Chin, 2010, p. 150) and instead focus on how multicultural experiences and competencies of these diverse leaders might shape their exercise of leadership regarding diversity in the athletic departments they lead. According to Eagly and Chin (2010):

The entry of individuals from groups that once had little access to leadership roles expands definitions of leadership. In the more varied environments that 
result, the experiences of leaders and their followers are qualitatively different from the experiences of those in culturally homogenous environments. The inclusion of individuals from diverse identity groups as leaders can thus change these roles to some extent. (p. 221)

There is a unique and insidious heritage of injustice and discrimination that African Americans have faced throughout U.S. history (Bell, 1992; Sage, 2007). This systemic racism (Feagin, 2006) is coupled with negligibly low numbers of racial minorities in leadership roles in sport (Cunningham, 2015). Thus, our focus on African American male ADs has the potential to provide important insight into the "qualitatively different" experiences of these leaders and their followers in the university athletic department environments that were created as a result of these leaders' presence.

In this current study, we move away from the traditional racial comparison among leaders (Singer \& Cunningham, 2012; Wyatt \& Silvester, 2015). Instead, we focus solely on African American male leaders, thereby allowing for the illumination of the voices and experiences of African Americans as nontraditional leaders in a traditionally White male-dominated world (see Livers \& Caver, 2003). African Americans as a racial group have historically been clustered closer to the bottom than the top of the American economy (Cokley, Dreher, \& Stockdale, 2004) and faced various institutional constraints and challenges with being Persons of Color at the top of the corporate ladder (Carbado \& Gulati, 2009; Livers \& Caver, 2003). Moreover, the few racial minority leaders who do successfully ascend to the top of the corporate ladder may not lift as they climb, or provide the benefits they are in a position to provide for other racial minorities in the organization (see Carbado \& Gulati, 2009). In this regard, our examination and comparison of the approaches to managing diversity of two African American male ADs in their respective athletic departments is important in and of itself. This collective case study allowed us to gain valuable insight into the leadership mindsets and behaviors of senior-level sport managers from this historically under-represented, marginalized group.

\section{Conceptual Framework}

We frame our work within the context of leadership in diverse organizations. In doing so, we acknowledge critical theorists who have raised some legitimate questions about the notion of diversity management (see, for example, Embrick, 2011; Kersten, 2000; Zanoni, Janssens, Benschop, \& Nkomo, 2010). These concerns notwithstanding, a number of scholars have focused on questions and challenges associated with leading a diverse workforce and strategies for effectively managing diversity within organizational settings (e.g., Chin, 2010; Chrobot-Mason, Ruderman, \& Nishii, 2013; DiTomaso \& Hooijberg, 1996; Thomas, 1990). In one of the early foundational texts on diversity in organizations, Cox (1993) defined managing diversity as "planning and implementing organizational systems and practices to manage people so that the potential advantages of diversity are maximized while its potential disadvantages are minimized" (p. 11). Cox discussed how (a) moral, ethical, and social responsibility goals, (b) legal obligations, and (c) economic performance goals are all facilitated by managing 
diversity in organizations. He also suggested that managing diversity is most crucial to the accomplishment of these organizational goals and, therefore, is at the core of leadership in organizations.

In discussing the role of leadership in the diversity management process, Cox (1993) asserted that leadership "refers to the need for champions of the cause of diversity who will take strong personal stands on the need for change, role model the behaviors required for change, and assist with the work of moving the organization forward" (p. 230). This definition suggests the leadership of a diverse workforce demands an approach where leaders are not only the targets of influence, but also agents of influence and change (Cunningham \& Sartore, 2010; DiTomaso \& Hooijberg, 1996). Thomas and Plaut (2008) contended organizational leaders establish the values and in many ways drive the cultures of organizations. They also asserted that leaders establish human resource policies and practices that can support or denigrate attempts at effective diversity management. Therefore, the values and practices of these leaders, particularly as organizational role models, are important to our understanding of why and how followers resist or embrace diversity. In this regard, a focus on leaders is crucial to understanding how diversity works and plays out in organizations.

Some of the early research in leadership and diversity management focused primarily on how leaders in organizations designed and implemented policies, practices, and processes to develop diversity within the management ranks (i.e., increased women and racial minority representation; see Morrison, 1992). Of particular relevance to our current study is Gilbert and Ivancevich's (2000) comparative study of two organizations at different stages in the diversity management process. One organization (deemed as multicultural) created more inclusionary practices and management systems than the other one (deemed as plural). These researchers found that leader initiation and support was the most important factor that contributed to the failure or success of diversity initiatives across these two different organizations. In comparison to his counterpart in the plural organization, the chief executive of the multicultural organization was explicit and intentional about his commitment to and support of diversity initiatives. Interestingly, although the racial background of this leader was not mentioned, the authors reported that his early childhood experiences in which he saw racism practiced prompted him to become a champion of diversity in his organization, focusing specifically on racial and gender diversity in his crusade to bring about change as he climbed the corporate ladder. This leader's emphasis on diversity had a major impact on his followers and set the tone for the human resource initiatives, organizational communication, corporate philosophy, and measures of success related to diversity in the organization.

More recently, Chrobot-Mason et al. (2013) discussed two theoretical positions that help explain how leaders accrue diversity capital. First, they emphasized that leaders shape and convey a meta-narrative or story about diversity within their organization through their style, behaviors, and values. They stressed how leaders are role models who both develop and implement diversity policies and practices for others to follow. According to Chrobot-Mason et al. (2013):

Because of their position, expertise, and/or authority, leaders demonstrate for others the extent to which differences are valued, employee subgroups are 
treated in egalitarian ways, and collaboration is encouraged. Thus, their behavior creates a story for others in the organization to follow. (p. 330)

These authors argued that leaders who are most successful in conveying their narrative to their followers are typically the ones who are motivated by their internal beliefs in the value of diversity (e.g., promoting justice, enhancing inclusion and well-being, achieving better strategic outcomes), not by external compliance motives (e.g., legal pressure, keeping up with competitors, avoiding bad publicity).

Second, Chrobot-Mason et al. (2013) focused on three primary approaches to managing differences that leaders might embrace while leading the organization and their followers. First, the hands-off or passive approach is common among leaders who might fail to see a problem with diversity in the organization, or choose not to address such problems out of fear that doing so will make matters worse between and among different groups in the organization. This approach is especially prevalent among dominant group leaders (e.g., White males) when their "own identity becomes a blind spot in the sense that the leader cannot see issues from other perspectives" (Chrobot-Mason et al., 2013, p. 330). Second, the direct and control approach involves a leader's focus on the law and regulations to address differences, or the implementation of explicit diversity policies that are aimed at discouraging harassment and discrimination in the organization. The third and final strategy was most effective and termed the cultivate and encourage approach. With this approach, leaders focus on creating a climate where positive interactions can be fostered between and among different groups, and engaging in practices and activities (e.g., diversity training, open dialogue) that lead to an inclusive organizational environment.

Chrobot-Mason and colleagues (2013) illuminated the importance of leaders communicating their intended diversity strategies and approaches, and the need for this communication to be aligned with their actions if they desire for their followers to develop shared understandings of the organization's diversity agenda. In the current study, we build upon and extend the aforementioned scholarship by focusing specifically on race and how these African American ADs actually thought about and carried diversity into practice. By focusing on perspectives of both these leaders and their followers, our research helps allay concerns about potential bias in research findings related to diversity in athletic departments. That is, there could well be a belief among some observers that top-level administrators might have more optimistic views of their department than do their subordinates (see Cunningham, 2008a). Therefore, we attempt to address this by also including the perspectives of the followers of these ADs. In this regard, our study was guided by the following research question:

Research Question 1: How do the leaders (i.e., two ADs) think about and approach diversity in their respective athletic departments?

\section{Method}

\section{A Qualitative, Collective Case Study}

The findings from this study are part of a larger research project aimed at understanding best practices of university athletic departments that had been 
recognized for their exemplary efforts pertaining to diversity. The primary aim of the overall project was to understand how athletic departments that consistently excel in the areas of diversity and inclusion do so-that is, how do they create and maintain excellence in diversity and inclusion? The athletic departments had previously won awards for their diversity and inclusion efforts and had, therefore, distinguished themselves from other departments. In this portion of the broader study, we focused on the two athletic departments within that group that were led by African American male ADs. Given that African Americans are unlikely to guide athletic departments-a point to which we previously alluded - these two departments were unique within the NCAA context.

We embraced what Stake (2005) refers to as a multiple case study or collective case study approach because this research design allows researchers to study more than one case jointly in order to examine a particular phenomenon, population, or general condition. While collective case studies are typically viewed as instrumental in nature in that the focus tends to be on examining the cases mainly to provide insight into a broader issue or to redraw a generalization, we actually took an intrinsic approach to the study of these two cases. In doing so, we acknowledge, as Stake (2005) noted, "there is no hard-and-fast line distinguishing intrinsic case study from instrumental, but rather a zone of combined purpose" (p. 445). In this vein, although the outcome of the research might involve some form of theory building and generalization or, more appropriately, transferability to other cases (see Flyvbjerg, 2006 for discussions on generalizability and qualitative case studies), the primary purpose is to better understand these two particular cases (i.e., athletic departments led by African American male ADs) and how they could potentially be similar to and/or distinct from one another and other potential cases.

Case study research involves the study of an issue explored through one or more cases within a bounded system (i.e., a setting or context; Creswell, 2007). In this instance, our focal point was on these two ADs and how they approach diversity in their respective athletic departments. It is important to note, however, that even though we were able to secure a single, lengthy, semistructured interview with each of these ADs and compile important biographical information on each via websites and other sources and documents provided to us, we did broaden our case studies to include the perspectives of other important athletic department stakeholders who could provide additional insight into the impact these leaders' approaches to diversity were having on the athletic departments as a whole. Stake (2005) referred to these as "cases within the case-embedded cases or mini-cases" (p. 451). In broadening the scope of our case study to include these mini-cases, we offer a more nuanced understanding into the social phenomenon under study. Our interviews with athletes, coaches, administrators, and other stakeholders within and outside the athletic department, as well as our gathering of additional information pertaining to the diversity practices within the athletic department (as well as the broader university) constituted an important part of this collective case study. Below, we provide a description of the context for each of our case studies, discuss the participants, particularly each AD's background, and outline our data collection and analysis approaches. 


\section{Athletic Department 1}

This athletic department is situated within one of the largest PWIHE in the United States. The university has been consistently ranked by the US News \& World Report as a top 20 national public university and as one of "America's Best Colleges." It has several centers and offices designed to address the diverse needs of students, faculty, and staff in terms of race, ethnicity, and nationality; sexual orientation and gender expression; physical and mental ability; and religion; among other diversity forms. Further, university leadership implemented a diversity action plan that is aimed at increasing diversity among students, faculty, and staff, and this continues to be a major focal point for the university's leadership, including the $\mathrm{AD}$ (who also was an associate vice president) at the university. The compositional diversity of the AD's senior leadership team, which, at the time of our study, included an African American female, two Asian American males, and an African American male, among others, is reflective of this reality.

The athletic department had over 300 employees on staff and was affiliated with one of the major Football Bowl Subdivision (FBS) conferences. It has a tradition-rich football program that has won several conference championships and multiple national championships, been consistently ranked in the top 25 of the Associated Press and Coaches' Polls, and sent several players to the National Football League (NFL). Completely self-supporting, the athletic department has one of the largest operating budgets among NCAA member institutions, which allows it to contribute financial support back to the university and support over 900 student-athletes by fully funding 36 varsity sports. Like football, many of these athletic programs (and the coaches and athletes in them) have achieved stature and standing on the national level. This is evidenced by the fact that the athletic department consistently ranks among the top 20 in the standings for the Directors' Cup, which is given annually to the nation's most successful athletics program. Several of the teams, individual student-athletes, coaches, staff, and administrators regularly claim championships, academic and athletic awards, and praise and recognition for their accomplishments.

The AD, who was in his fourth year at the time we interviewed him, had accumulated over two decades of experience in that role at other PWIHE before coming to this current athletic department. He not only brought with him this experience from these previous posts, but also a business degree and background from having worked in corporate America for a few years. He has also amassed several awards and been recognized for his leadership abilities and business acumen by the SportsBusiness Journal as well as other publications and various organizations (e.g., Black Coaches \& Administrators [BCA], National Association of College Directors of Athletics [NACDA]). In addition, he emphasized a visionary leadership style and strategic plan that emphasizes the development of the total student-athlete. This focus stems, at least in part, from his experiences as a former college athlete and football coach. Through the strategic plan, this AD stressed his goals and aspirations to provide transformational opportunities for gifted young student-athletes by affirming "a higher purpose" for these athletes beyond the athletic arena. In addition to his passion and concern for the educational development of student-athletes who come through the athletic department, he was also active with various student groups within the broader university campus 
community, as well as with youth groups in the local community of which the university is a part.

\section{Athletic Department 2}

This particular athletic department is affiliated with a major PWIHE that was established as part of the state university system, and is one of the largest universities in the nation. The main campus is spread out over several acres of land, and it serves over 50,000 students. The visionary and energetic leadership of the university president has allowed the university to expand and grow in areas such as medicine, engineering and computer science, education, and business administration. Furthermore, the president's commitment to diversity was reflected in the fact that he was able to recruit and hire a prominent scholar who studies diversity in sport to set up an institute within one of the major colleges at the university.

The athletic department had a staff of about 150 employees from various backgrounds, and it serves roughly 500 student-athletes in 16 varsity sports, the minimum number of sports required for NCAA FBS status. Although the athletic programs did not belong to what was known as one of the "Big 6" FBS conferences -meaning the football team does not earn an automatic qualifier bid to one of the Bowl Championship Series (BCS) games-they do belong to one of the other tradition-rich, nationally-prominent conferences. This athletics department has gone through a period of rapid growth and development in recent years, including its transition through several conference affiliations where the football team participated as an FBS independent (i.e., "football-only" member). In efforts to remain competitive at the highest levels of college sport, particularly in the revenue-generating sports of football and men's and women's basketball, the athletic department invested in a new football stadium and basketball arena.

The AD, who was in his second year at the time we interviewed him, came to the position with several years of work experience in college sport and corporate America. Although he never had aspirations to coach, his love for sport and athletics, which was cultivated by his participation in sport (particularly football at the college level) led him to believe he could be in charge of a program as an AD at a major university. He discussed during his interview how he literally learned every aspect of athletics as he pursued his goal of one day becoming an AD. This gave him credibility as a leader with those who worked under his guidance within the athletic department, as well as with his peers from across the country. This is evidenced by the many awards and recognitions he has garnered over the years from various organizations (e.g., BCA, NCAA) and publications (e.g., Sports Illustrated), and the praise he has received from his many colleagues in college sport. As the leader of this athletic department, this AD first emphasized studentathlete graduation while also striving to win championships in the various sports they play.

\section{Data Collection and Analysis}

In conducting qualitative case studies, researchers generally spend extended time on site, personally in contact with activities and operations of the case, reflecting, 
and revising descriptions and meanings of what is occurring. However, as Stake (2005) noted, the time we spend concentrating our inquiry on a case may be long or short, but while we so concentrate we are engaged in case study. Although we only had access to each research site for a 2-3 day period, we were still able to gather some useful information for each case. We took a multi-method, qualitative, datagathering approach consisting of: (a) the review of relevant documents (i.e., information from athletic department and university websites, literature provided by the athletic department personnel); (b) 30-90 min semi-structured interviews with each AD and various stakeholders of the athletic department; and (c) field notes taken by the two researchers during the visit to each campus. This triangulation of data sources served as one mechanism for establishing trustworthiness and credibility for our research study.

Access to the athletic departments was secured with the assistance of the NCAA. Once the NCAA connected us to the athletic departments, we worked with important stakeholders at each university in gaining access to and setting up a campus visit and schedule of interviews with the $\mathrm{AD}$ and the other participants. In addition to each $\mathrm{AD}$, we interviewed several other stakeholders of the athletic department at each university. There were a total of 13 other interview participants from athletic department 1 (see Table 1). For athletic department 2, there were five additional interview participants (see Table 2).

We asked each of the participants during our interviews questions that focused broadly on their conceptions of diversity, the most salient dimensions of diversity in the athletic department, the diversity-related benefits and challenges, strategies and tactics for creating and sustaining diversity in the athletic department, and practical advice for nurturing diversity in intercollegiate athletics. More generally, we made certain to engage in the process of member checking as yet another way to

\section{Table 1 Athletic Department 1}

\begin{tabular}{lll}
\hline Participant/Role & Race & Sex \\
\hline Athletic Director (AD) & African American & Male \\
Senior associate AD, finance \& operations & Asian American & Male \\
Assistant AD, development & Asian American & Male \\
Assistant AD, sport administration & African American & Male \\
Assistant director, communications & African American & Female \\
Human resources coordinator & White & Female \\
Director, strength \& conditioning & African American & Male \\
Athletics travel coordinator & White & Female \\
Assistant men's track \& field coach & African American & Male \\
Assistant women's lacrosse coach & White & Female \\
Director of human resources & White & Male \\
Faculty, athletics council & White & Male \\
Football athlete & African American & Male \\
Soccer athlete & White & Female \\
\hline
\end{tabular}


Table 2 Athletic Department 2

\begin{tabular}{lll}
\hline Participant/Role & Race & Sex \\
\hline Athletic Director (AD) & African American & Male \\
Associate AD, marketing \& communications & White & Male \\
Assistant AD, compliance & White & Female \\
Assistant AD, development & White & Male \\
Head women's basketball coach & African American & Female \\
Football athlete & African American & Male \\
\hline
\end{tabular}

establish trustworthiness and credibility. Member checking is a process that can occur during the interview process or through the analysis, interpretation, and write-up of the data. This process allows qualitative researchers to confirm or verify that they are accurately capturing the perspectives of the participants. Because we only had a limited amount of time with and access to the participants in our study, we focused on member checking primarily during the interview process. For example, at various times throughout the interviews, one or both of the researchers would (a) ask follow-up questions and ask the participants to expound upon or clarify a particular point they might have been making, (b) ask them to verify whether or not certain interpretations we had were accurate, (c) ask our interviewees to elaborate upon information we might have read in documents we reviewed, and (d) ask them to respond to comments or points other participants in the study made about diversity in the athletic department.

The majority of these interviews were audio recorded, and later transcribed by a research assistant. In those few instances where interviews were not audio recorded (e.g., participant preferred not to have interview recorded), we took detailed field notes that were later typed. In fact, taking field notes during each interview, whether it was audio recorded or not, was an important part of the data collection and analysis process. Moreover, we also included in our field notes some general and specific observations we made during our physical presence on campus and within the athletic department offices. For example, we made general observations of the demographic makeup of employees in the athletic department offices (e.g., the vast majority of the secretaries, receptionists, or offices assistants in athletic department 2 were young African American females).

A general inductive approach (Thomas, 2006) to the analysis of the qualitative data derived from this study was employed. The focus was on determining the core meanings evident in the text, and what categories and themes were most relevant to the research objectives identified. Again, the primary objective of this research study was to garner an understanding of how African American male ADs think about and lead diversity efforts in their college athletic departments. Although our approach to the analysis of the data was primarily inductive in nature, in that we allowed categories to emerge from the data, it was also deductive in the sense that the conceptual framework we used to guide this study helped inform our findings. We acknowledge that as researchers conducting field-based, qualitative research, our preconceived notions and biases could have impacted how we analyzed and 
interpreted the data. That is, we did not enter into the research process devoid of inclinations about what we might find or uncover. But, ultimately, we relied heavily on the words of the participants in the study to lead us toward the themes we identified. In fact, the first author, a Black male who specifically embraces qualitative research as a most effective approach to research with Black and other People and Communities of Color, and the second author, a White male who embraces more of a quantitative approach to the study of diversity issues in sport organizations, began the process of preliminary data analysis and interpretation during the actual data collection process (e.g., in between interviews with various participants) by engaging in initial conversations about what potential themes were beginning to emerge before we left the field. But it is important to note that it was the first author who took the lead role in interviewing the African American male ADs and their followers, and the second author played a very limited role in the data analysis and interpretation process once data collection ended.

The first author served as the primary facilitator in analyzing and interpreting the data once we left the field. More specifically, he first did an initial detailed reading of relevant documents, the typed field notes, and interview transcripts, and developed some basic, preliminary insights about the data via the process of note taking. This memoing process allowed him to begin explaining and elaborating on the coded categories that were emerging, and describing some specific aspects of the research setting and phenomenon under study (see Schwandt, 2007). During subsequent readings of the field notes and interview transcripts (i.e., the second and third iterations), the first author implemented a color coding scheme by hand as a way to begin identifying the different categories and themes that emerged from the raw data. That is, he literally utilized different colored markers (e.g., orange, green, yellow, blue) to highlight key words, phrases, and sentences from the raw data that spoke to these African American male ADs' mindsets and behaviors related to diversity in their athletic departments. Although he did not use a code book per se, the color coding scheme used by the first author did produce some initial categories that were eventually collapsed into the two broad themes presented in the findings below. Our interviews with the study participants focused primarily on how they defined diversity, what they considered to be the most salient forms of diversity in their athletic departments, and what the key elements were to creating and sustaining diversity in their athletic departments. Words or phrases such as "race", "gender", "racial minorities", "women", "leadership positions", "role model or role modeling", "mentor or mentorship", "empowerment", and/or "open and honest communication" were repeatedly mentioned across most of our interviews with these ADs and their followers.

It is important to note that since the focal point of this collective case study was on the two ADs, the data pertaining directly to each of them served as the starting point for the creation of the categories and, ultimately, the themes reported below. That is, the first author created the initial categories and themes from the analysis of primarily the data that were collected directly from or about each AD. The first author then continued analyzing the data from the other participants to see how their perspectives on diversity converged with and/or diverged from the perspectives of the AD. This approach allowed the first author to identify any potential negative case analyses (i.e., outlier data that might contradict the major themes), which is another important approach to establishing trustworthiness and credibility 
in qualitative research. While there were some followers who viewed diversity as more than just race and gender, the ADs and their followers were, for the most part, in alignment with each other in terms of how they thought about and experienced diversity in these athletic departments.

Because the participants for this study were essentially preselected and most, if not all, of them expressed favorable attitudes toward this topic of diversity, we acknowledge the possibility that the findings reported below were impacted by this reality. It is very possible that these athletic departments only granted us access to those participants who held positive attitudes toward diversity, and did not allow us to interview or interact with those who did not. The inclusion of the voices and perspectives of athletic department employees and stakeholders who might not have shared the sentiments that were expressed by the ADs and their followers in this study could have certainly added nuance and complexity to our understanding of how diversity played out in these athletic departments. In this regard, we understand this selection bias placed limitations on our findings. But, nonetheless, we do believe that our interviews with the participants that were included in the study provide important insight into diversity in these university athletic departments.

\section{Findings and Discussion}

Before discussing the major findings, we highlight noteworthy similarities between the two ADs in our study. In particular, they both (a) were in their early 50s and had families (i.e., wives and children), (b) grew up in major U.S. cities with a high concentration of racial minorities, (c) played football in college, (d) had business backgrounds and considerable work experience outside of the sport industry, (e) had a passion for connecting directly with student-athletes, and (f) were actively engaged with the broader African American community. In discussing our findings, we examine the similarities and any notable differences between the two athletic departments and these ADs' diversity mindsets and approaches. The primary themes that emerged across both athletic departments include a focus on: (a) increasing racial and gender representation in leadership positions and (b) utilizing diversity as a mechanism for role modeling and mentoring of athletes and employees. In addition, an important finding was the leader in athletic department 1 , unlike his counterpart in athletic department 2, explicitly focused on conducting an organizational analysis and making diversity training for all employees mandatory.

\section{Increasing Racial and Gender Minority Representation in Leadership Positions}

In efforts to garner these ADs' perspectives on diversity and how they approach it in their respective athletic departments, it was important to understand how the term "diversity" was defined or conceptualized by these leaders and their followers and how this understanding of it was manifested. When asked what diversity meant to them, both ADs and the overwhelming majority of their followers thought first and foremost of the racial and/or gender dimensions of diversity. Moreover, similar 
to Morrison's (1992) study there seemed to be a mindset that dealing effectively with diversity begins not only with the acknowledgment of the salience of race and gender, but also the inclusion of women (i.e., gender minorities) and People of Color (i.e., racial minorities) in the leadership, decision-making ranks of the athletic departments. In responding to the researchers' question about the meaning of diversity to him, the AD in athletic department 1 had this to say:

You know, it's unbelievable to have people in our society who have not had the opportunity to experience it and ultimately truly understand it. If you participate in a sport, you basically understand it because it's team building 101. Bringing a group of people together to work toward one common goal; that's the definition of team. So in order to be successful you have to bring people with all different types of talent and skills; and invariably they're going to have different backgrounds socioeconomically, ethnic backgrounds, indigenous backgrounds, people with rural versus urban backgrounds; and so all those things in my view represent diversity. The most successful teams, the most successful organizations have that mix of talent and experiences and so for me, you know it's who I am. It's what I was blessed to be a part of from the time I started playing sports. A locker right next to a White guy who was from a farm, you know I was from [name of city], and getting to know him, and appreciating his talents and skills. So when I think of diversity, I think of it from that view. I want to bring the total sum of all our experiences, so I want to bring people who have a multitude of different experiences together to be a part of the collective so we can ultimately reach our goal. (emphasis added)

This AD's commentary on diversity reveals his belief in the power of the sport context in helping to foster and facilitate the effective management of diversity. He believed team sport participation forces people from different backgrounds, particularly racial, ethnic, and cultural, to come together for a common purpose. His previous sport participation experiences contributed greatly to how he thinks about diversity in his athletic department, and how diversity contributes to success within the department.

Similarly, his peer in athletic department 2 also discussed the power of the sport context and the importance of bringing people together from various backgrounds in helping his organization to reach a common goal. In discussing the importance of diversity, he stated:

It's necessary because it brings diverse and different things to the table; different perspectives. I always like to surround myself with people who can bring something to the total . . . experiences from their prism. There are definitely experiences from a female perspective than a male perspective, no question about it. There's definitely a different perspective from a Hispanic and an African American. So as you're talking about things you want to do for student-athletes and for the program, and if you hear something from other people's perspective you could probably make a decision that's going to be in the best interest of everyone ... I find that we've made probably acceptable decisions where it's palatable to everyone when you look at it in totality. 
As can be seen from these two ADs' commentaries, both demonstrated an affective commitment to diversity or a belief in the inherent benefits of it (see Cunningham, 2008a), particularly racial and gender diversity. Moreover, our interviews with each revealed that they both felt their respective athletic departments were limited or lacking in these areas when they first stepped into their respective leadership roles. This had an impact on how they both conceptualized diversity and their decisions to pay attention to race and gender in their approach to dealing with diversity. According to the AD in athletic department 1:

We were not as blessed to have as many People of Color, particularly in our leadership teams. So I focused hard on increasing the number of People of Color in our department, but also in leadership positions. We didn't have women in leadership positions. We had a large number of women but not in leadership positions. So I focused hard on identifying some young women who could be in leadership positions and then we openly talked about that. I didn't shy away from it. I wanted people to feel comfortable talking about it.

This AD insisted that a part of the strategic planning process he engaged in with his followers upon taking over the leadership reigns in the athletic department involved open and honest communication about the need for everyone to embrace diversity in general, but, more specifically, the need for an increase in racial and gender minority representation in the leadership ranks. This leader took on the mindset that in order to make diversity work, leaders must be "authoritative" and "affirmative" in communicating this mandate to their followers. He stated, "If you want to have, want to create that rainbow of different people, sometimes you have to be definitive and force it."

This focus and emphasis on greater racial and gender minority representation in leadership positions as a major priority in the athletic department was illustrated in the myriad of examples that several of this AD's followers shared. In particular, the human resources director, an individual who is involved in the hiring process for most all employee positions in the department, shared that during the hiring process for positions in the department, the AD "will come in on a regular basis when we've got jobs open and say, 'what's our pool look like? Do we have qualified people? Do we have any females in the pool? Do we have any minorities in the pool?' Stuff like that, because he's really interested in it." When asked how this AD understands and illustrates the value of diversity, several other followers offered great insight into his strong commitment to increasing racial minority and female representation. For instance, the assistant AD for development stated:

I just look at the dynamics of our office. I mean we changed significantly. I mean when he got there, he promoted me and we hired a female. Our first fulltime female fundraiser, and then since that point we've added, you know, my replacement was an African American female. We hired an additional fundraiser who is an African American male.

As another example, the assistant director of athletics communication suggested the leadership team had an explicit, intentional focus on hiring personnel who did not fit the historically-dominant, White male demographic: 
I think our department has made it a point of trying to hire more women . . . I think it's kind of been put out there last year. We had some staff changes and they were interviewing for a new AD for communications, assistant athletic director for communications. It was mentioned that, you know that they wanted a woman in that position; and so I think that . . . the only logical explanation was that you wanted to put a woman in this position because you didn't want to be like, "oh, okay, we hired a 40-year-old white male for this position."

Similarly, comments from the assistant AD for sport administration helped corroborate his fellow colleagues' perspective on how the AD and his leadership team were greatly concerned with increasing the presence of racial minorities and women in important leadership positions. According to this participant:

I think number one, you know not so much just racial diversity but diversity in terms of gender, opportunities for women in the department. I think for us it's key leadership positions ... . You know so diversity is almost empowering because of the key positions you have. You could have a diverse staff; and not that it's a bad position, but you can have all janitors you know so your numbers look good; but are people in decision-making positions? And I think that's the next step in athletics that we're seeing a wave of young administrators that are more diverse in their experiences, not just compliance and academics or football coaches. You're seeing them in marketing and development; they're in decision-making opportunities. That's where I see diversity; it's continuing to have individuals in those key decision-making positions as minorities and women. (emphasis added)

This focus on racial and gender diversity in leadership and decision-making positions was something the $\mathrm{AD}$ and most all his followers consistently mentioned as being important to the organization.

Although the vast majority of the participants from athletic department 1 viewed the concept of diversity first and foremost from a race and gender perspective, there were a couple participants who challenged this narrow conceptualization of diversity. For example, the assistant director of athletics communication discussed how, at first, when she thought about what diversity meant to her, she "got into the trap" that it is just a Black and White racial thing, later recognizing that diversity includes other important things such as one's age and ability status. Similarly, the women's soccer player we interviewed discussed from her perspective how the younger generation feels that a focus on race is not as important anymore, and she would advise athletic department leaders that the "next hurdle to get over is sexual orientation" in athletic departments.

The AD in athletic department 2 had a similar diversity mindset and approach as his peer in athletic department 1. Like his peer, this AD acknowledged that the athletic department was lacking in racial and gender diversity when he first took the reins of leadership. He discussed how "we're fortunate that we have a president that believes in diversity and believes in diversity in athletics in particular." In responding to a question about some of the challenges associated with managing and dealing with diversity in his athletic department, this AD stated: 
I think my biggest struggle has been really identifying and diversifying what I call senior leadership more than what it is today; and what I've tried to do is when opportunities present themselves is to make sure that I identify those diverse candidates that fit; that fit me; that fit what we're trying to do.

Interestingly, the challenges associated with identifying "diverse candidates that fit" for this $\mathrm{AD}$ and what he was trying to do were manifested during a particular time when he hired an African American male into an assistant AD position, even though he had reservations about doing so. In his words:

I hired a gentleman because he's African American and I wanted to have one Black on my staff . . . I should have waited because he didn't work out. I probably knew he wasn't the right guy when I hired him; but it was a commitment that I believed in and that I wanted because I didn't want to walk in my meeting room and, you know (a) I'm the only African American, or (b) I have only one female in there.

This quotation above highlights a key difference between the ADs. Although both championed for and intentionally sought a diverse staff, the AD in athletic department 2 hired someone seemingly primarily based on the person's race. $\mathrm{He}$ later recognized that his reservations about hiring this particular employee were well-founded and on point. Such personnel practices can spur legal questions and potentially elicit backlash from others, especially White men (Harrison, Kravitz, Mayer, Leslie, \& Lev-Arey, 2006). We did not discern such an approach from the $\mathrm{AD}$ in athletic department 1 . He challenged people, made them justify their homogeneous applicant pools, and routinely sought a diverse workplace; but, he did not sacrifice applicant fit for the sake of diversity. Instead, for the AD in athletic department 1 , diversity and excellence went hand in hand.

We do recognize that the $\mathrm{AD}$ in athletic department 2 relayed this decision in the conversation pertaining to his commitment to diversity. According to the $\mathrm{AD}$, a focus on diversity in hiring is "a conscious effort with me, and I think my staff knows it's a conscious effort; and it's something that I want them to pay close attention to. I don't tell them who to hire, but they know that it's important" to pay attention to having a diverse pool of candidates (i.e., people from historically under-represented groups such as women and racial minorities) when making hiring decisions. Thus, as a member of the African American community, he felt a duty to provide opportunities to his fellow in-group members (see Slay, 2003, for an interesting discussion on how African American leaders negotiate the potentially conflicting primary social identities of corporate executive and African American).

As an example of this AD's commitment to creating opportunities for women and People of Color in his athletic department, the assistant AD of compliance discussed how proactive the $\mathrm{AD}$ was in seeking out and hiring female coaches for women's teams. This was reflected in the fact that, according to this participant, "before our women's volleyball coach change ... he had every female program coached by a female head coach." She acknowledged that this AD and his leadership team went beyond simply posting positions for head coaching jobs, and actively went out and sought quality female candidates for the head coaching positions. This proactive approach to hiring women's head coaches for women's 
teams was evident when the AD hired an African American female as the head coach for the women's basketball team. Multiple participants in the study shared how the coach who was ultimately hired was one of three African American females in the final pool of candidates for this position. In our interview with this head women's basketball coach, she discussed how proactive the AD was in building and nurturing a relationship with her over several years, and this ultimately culminated in her being hired into the position.

The narratives from our participants across both athletic departments reveal the African American male ADs in our study were explicit, bold, and unapologetic in their commitment to providing leadership opportunities for racial minorities and women as a key aspect of effectively approaching and incorporating diversity in their athletic departments. Similar to the leader in the multicultural organization in Gilbert and Ivancevich's (2000) study, the ADs in our study were committed to the recruitment and hiring of racial minorities and women into formal, major decisionmaking leadership positions (e.g., head coaches, associate and assistant ADs). Eagly and Chin (2010) suggested racial minority leaders in organizations are particularly concerned with integrity and justice, especially as it relates to the inclusion and treatment of individuals in social groups that have historically been marginalized in society and various social institutions. The African American male ADs in our study embodied this ideal and took a proactive approach (see Fink \& Pastore, 1999) in their recruitment and hiring of racial minorities and women into key leadership positions within their respective athletic departments.

\section{Utilizing Diversity as a Mechanism for Role Modeling and Mentorship}

Related to the first theme of diversity being understood and manifested as the representation of racial minorities and women in leadership positions, the second theme focused on the positive impact this representation could have on key stakeholders (particularly athletes) in the athletic departments. McCarty Kilian, Hukai, and McCarty (2005) discussed the importance of senior management in organizations creating a diversity strategy that includes, among other factors, demographic changes in the workforce and the need for visible role models. Cunningham (2008b) observed similar patterns, as athletic administrators in his study suggested that diversity in top leadership was important because of the role modeling functions that followed.

We discussed with the AD in athletic department 1 how and why he felt having more racial minorities and women in leadership positions would help him to achieve some of the goals, particularly related to diversity, he had for his organization. This is where the issue of role modeling and mentorship first surfaced as being critical to what he was attempting to accomplish in the area of diversity and addressing the needs of the various personnel in the department. According to this leader:

Role modeling is critical for all of our athletes . . . you know kids model people and respect them and so on and so forth . . . a young female who may aspire to be a leader besides the coach, and in most cases unfortunately in college sports there's more men coaching women's sports. Well if you don't have any other leaders that those people can role model after then you're not providing that 
one element that will help provide success. Same thing with People of Color, just practically because I was blessed to be in the position that I'm in I'm able to deal with some of the Black issues with some of our players because when they come into my office as a result of whatever they look at me differently. Whether we want to admit it or not, that's an asset I have. So I use it, and so the other thing is, you know I become . . . inspirational for them . . . So there's a multitude of things but ultimately it's just role modeling and I think that's very important for us to be successful. (emphasis added)

This AD's focus on role modeling and assertion that his being in the leadership role of AD as an African American male is an asset that helps him to "deal with some of the Black issues with some of our players" provides powerful insight into the diversity mindset of this AD. His narrative suggests it is important that athletes have strong examples and advocates from historically marginalized, under-represented groups in influential leadership positions in the athletic department. This allows young people to (a) have someone with whom they can relate and who can help them with the challenges they face, and (b) have a role model to look to as an inspiration and motivation during and beyond their time as athletes at the university (see also Cunningham, 2008b).

The AD in athletic department 2 echoed the sentiments of his peer in athletic department 1 . He likened the athletes in his programs to his "grandkids", and discussed the important role he and other leaders in the athletic department (particularly coaches) played in nurturing the development and serving the needs of the athletes in the athletic department. For example, in discussing the importance of having women in head coaching positions and the positive impact this could have on female athletes, he stated, "I believe what they see is what they will be, and I want our female athletes to see a female in power, in a leadership role because that gives that confidence, you know, 'I can be a head coach or I can be this or that." He also mentioned how important it was for all athletes in general, but Black athletes in particular, to see him "sitting in the AD's chair" as a Black male because it could give them something to aspire to beyond just being an athlete. The African American male football athlete we interviewed acknowledged how significant it was to have a role model like this AD to serve as an example and mentor for young Black athletes in the athletic department. He discussed how, in comparison to the previous $\mathrm{AD}$ (a White male), he knew this current $\mathrm{AD}$ "on more of a personal basis" and interacted with him on a regular basis. In his words:

Seeing him in that position, and the job that he's doing and the acceptance that he's received since he's been here . . . I mean since he's been here it's been nothing but positive as far as what he's putting out, and the people around him that are supporting him. I think for young African Americans that is really motivating to know that if you work hard, and do what you are supposed to do you can make it and do something as important as what he is doing and the support for you will be there.

This athlete's narrative speaks to the potential impact the presence of diverse leaders as role models and mentors could have on the aspirations and overall educational experiences of athletes in these athletic departments. 
The presence of these two African American ADs as the leaders of their respective athletic departments also positioned them to be role models and mentors for the employees that worked with them and under their leadership. Several of the followers across both athletic departments reflected upon and discussed the impact that having these diverse leaders in place had on them as individual employees, and diversity in the athletic department as a whole. For example, the assistant AD for sport administration, an aspiring leader who participated in the NCAA leadership institute for ethnic minority males, discussed the important mentorship role the AD in athletic department 1 played in helping him to reach his goals to one day become an AD. He stated, "I have an aspiration to be an athletic director. I think I'm learning from, you know, the best guy in the business. You know so I can walk behind him for 25 more years if it has to happen that way." As another example, the senior associate $\mathrm{AD}$ of finance and operations discussed the importance of mentorship and described the $\mathrm{AD}$ as "somebody who really takes a personal interest in you, and tries to work and help you develop" by pointing out your strengths and weaknesses and providing suggestions for improvement. He further discussed how one of the reasons he came back to the university was to work specifically with this $\mathrm{AD}$ because, according to this participant, the $\mathrm{AD}$ is a role model and "has always been one that I'd love to try and emulate." His desire was to listen and learn as much as he could from the $\mathrm{AD}$ as he continued his preparation to assume an $\mathrm{AD}$ role one day.

In a similar vein, the assistant $\mathrm{AD}$ in development, who also was a participant in the NCAA leadership institute, expressed how fortunate he was to work under the guidance of this AD. According to this participant, "Our AD is a wonderful man to work for. You know, he's a wonderful teacher." He further shared how "there's a great, great culture of mentorship and nurturing to help you through the business." This participant and other participants in our study alluded to how the "culture of mentorship" that has been created under the leadership of the AD not only benefited them as internal stakeholders of the athletic department, but it also benefited some external stakeholders outside the athletic department. For example, in our interview with the travel coordinator, she discussed how the AD was preparing to host the Black ADs' seminar, and how this type of diversity outreach has been the norm under his leadership:

It's something that he has done and I think it's a regular group that meets, but he's not looking for any accolades because he doesn't need that because he is doing ... He doesn't need validation that he's doing it. He knows he's doing it. We know he's, I know he's doing it. And I think that's what it is; it's the quiet stuff, the stuff that just becomes habitual, not low key; but just this is normal life for us. This is how we operate. We include; we go out and find; we invite in; we empower.

These quotes speak to the culture of mentorship and role modeling this AD created in this athletic department, and the impact it had on his followers and other stakeholder groups outside the athletic department (i.e., racial minority administrators from other universities).

Unlike the interviews with our participants (i.e., employees) in athletic department 1 , the interviews with the participants in athletic department 2 did 
not yield the same types of rich narratives about role modeling and mentorship. One plausible explanation for this could be that we interviewed less than half the number of people in athletic department 2 than we did in athletic department 1 , and, of those we did interview, none were racial minority administrators like the many we interviewed in athletic department 1 . However, it was evident from our site visit and interactions with employees in athletic department 2 that his followers viewed this $\mathrm{AD}$ as a strong role model whose vision for diversity and excellence was one worth getting behind. This was reflected in the statement by the assistant AD of compliance when she stated, "you know when you work for someone who lives what they say, it's easier than when you work for someone who just says and doesn't live it." This quote suggests this AD was indeed a role model who led by example when it came to matters of diversity in the athletic department.

Research on role modeling and mentoring has revealed that women and racial minorities have greater challenges finding role models and mentors of a similar demographic background who are in formal high-ranking leadership positions in the workplace, and who are able and willing to help them advance to greater heights in their careers (Livers \& Caver, 2003; McCarty Kilian et al., 2005; Wyatt $\&$ Silvester, 2015). Executive women and People of Color have reported that having mentors and role models was an important factor in their career development (McCarty Kilian et al., 2005). Although, to our knowledge, these athletic departments did not have formalized mentoring programs firmly in place, there did appear to be a "culture of mentoring" and role modeling across both athletic departments, particularly as it relates to addressing the needs of athletes in these programs. One of the primary reasons both ADs were adamant about hiring more women and racial minorities into leadership positions was so they could serve as role models and mentors to the athletes in the athletic programs. Moreover, these ADs viewed themselves as important role models and mentors to the racial minority athletes in particular, but all athletes in general. Finally, the followers who worked directly with and for these ADs looked up to them as strong role models and mentors.

\section{Organizational Analysis and Diversity Training}

Cunningham (2015) discussed the importance of engaging in a needs analysis before embarking on diversity training and other diversity-related efforts in sport organizations. He also discussed the importance of the organizational analysis as the critical first step in the needs analysis process. Participants across both athletic departments mentioned their experiences with diversity training and the importance of these educational activities to the diversity efforts in their respective athletic departments. However, athletic department 1 was the only one of the two athletic departments where there was an explicit engagement in an organizational self-analysis to assess who they were as an organization before requiring employees to partake in the diversity training that the $\mathrm{AD}$ explicitly mandated. Our interview with the senior associate $\mathrm{AD}$ of finance and operations in athletic department 1 provided some insight into the significance of the self-analysis to their diversity efforts. According to this participant, "I think what the self-analysis told us was that number one ... we need to do a better job of figuring out who we are. Identifying it, putting it down on paper and having our beliefs and everything 
in front of us." This process led to the creation of a brand framework that the athletic department used to espouse its beliefs, focus, and purpose. Essentially, athletic department 1 created a brand identity that focused on providing "remarkable experiences" for all its stakeholders, but particularly the athletes, who were viewed as the future leaders of communities beyond the athletic department.

When pressed during the interview to further explain how this brand framework ties into the issue of diversity in the athletic department, the senior associate $\mathrm{AD}$ of finance and operations stated:

"I think, that this self-analysis, this inside-out analysis, also told us much like what the attitudes were inside the department ... I think what was identified is that you have this change agent leading the way who is finally starting to break down a lot of the, what was happening. I mean, this department for years operated in so many different silos, departments not talking to each other, not cooperating, not being efficient, and not being effective because they were operating in all these different silos.

The AD was indeed the "change agent leading the way" in breaking down the silos and bringing people together across the department to work toward common goals. This leader utilized this self-analysis conducted by an outside consulting group as a mechanism to examine the challenges the department faced and to create opportunities to improve in certain areas, including diversity.

Our interview with the AD provided further insight into how the self-analysis impacted diversity efforts of the department under his leadership. In particular, he spoke to the need for employees in the department to "understand the value of setting goals and objectives and ultimately being evaluated." $\mathrm{He}$ shared with us how before he came to the department and took over as AD there were a great number of employees who had never been evaluated and held accountable for their performance in meeting goals. In this regard, one of the primary goals to come out of the self-analysis was the need to really focus on specifically increasing racial and gender diversity among employees (particularly in leadership positions) in the department, and be able to talk about it openly and candidly. According to the AD, "everyone bought into 'we want diversity'; and everybody bought into that we had to be forthright and candid about how we're going to make this happen." In this leader's mind, the "self-assessment allowed us the platform to communicate and talk about things and be open." As a result, this allowed this leader and his followers to get on the same page regarding expectations related to diversity efforts in the department.

The organizational self-analysis that athletic department 1 engaged in allowed the $\mathrm{AD}$ and his followers to identify and assess pertinent issues and challenges within the organization, including those related to diversity, and determine what was needed to begin addressing them. As previously noted, it helped open lines of communication so that employees could freely discuss important issues in the workplace, particularly related to diversity. Doherty and Chelladurai (1999) discussed how an open line of communication is one of the key attributes of sport organizations that have organizational cultures of diversity. Moreover, when sport organizations combine a culture of diversity with high levels of cultural diversity among employees, they tend to realize the most benefits of diversity. Both 
athletic departments in our study exhibited aspects of an organizational culture of diversity under the leadership of their respective ADs, and had high levels of cultural diversity among their employees. This was particularly the case in athletic department 1.

Findings from the organizational self-analysis in athletic department 1 encouraged the $\mathrm{AD}$ to bring in an outside group to facilitate diversity training sessions that were designed, at least in part, to help begin breaking down the silo mentality that was pervasive in the athletic department. Cunningham (2012) highlighted the positive outcomes of such diversity training, particularly when linked with the strategic initiatives. The findings from our research in athletic department 1 revealed that this training yielded benefits such as enhanced knowledge and understanding between and among employees. That is, not only did this training improve employees' knowledge about diversity, but, more importantly, it allowed employees from different backgrounds to learn things about each other that perhaps they otherwise would not have learned in the absence of this diversity training. This certainly could have implications for improved intergroup relationships across the various groups and silos within the athletic department.

\section{Implications, Future Directions, and Conclusions}

In this study we sought to understand how African American male ADs as diverse leaders think about and approach diversity and its impact on their followers. Consistent with Tsui and Gutek's (1999) contention that people are most often referring to the presence of women and racial minorities when talking about diversity in organizations (see also Singer \& Cunningham, 2012), our findings here suggest that the leaders and followers in both athletic departments viewed diversity primarily from a race and gender standpoint. But, this current study also revealed the leaders' heightened attention to race and gender (see Livers \& Caver, 2003), specifically their focus on the presence and empowerment of women and racial minorities in actual leadership positions (and the leadership pipeline), as an important and necessary approach to fostering diversity and inclusion in their athletic departments. Moreover, participants across both athletic departments believed the presence of racial and gender diversity in key leadership positions serves as an effective mechanism for providing role models and mentors for stakeholders in the organization, particularly female and racial minority athletes. Lastly, the primary difference between the leadership in athletic department 1 and athletic department 2 is that the former, unlike the latter, explicitly engaged in an organizational analysis to help inform formal diversity training and other efforts related to diversity in the athletic department. This is not to suggest that athletic department 2 did not have some form of an organizational analysis or diversity, but it does suggest that it was not made explicit during our study. In the following space, we briefly discuss contributions this research makes to the literature, implications for policy and practice, and future directions for research.

In regard to contributions to the literature, the ADs in our study seemingly embody what Cox (1993) meant when he defined the term leadership in his discussion of the role that leaders play in the diversity management process. That 
is, these African American male ADs were champions for the cause of diversity, took strong personal stands on the need for change, and showed a commitment to moving their respective athletic departments forward, particularly via the hiring and empowerment of women and racial minorities into leadership positions and the leadership pipeline. They seemed to view this racial and gender diversity as more than simply a bottom-line business imperative, and recognized it as a moral obligation. They exhibited both an affective commitment (i.e., belief in the inherent benefits of diversity) and normative commitment (i.e., sense of obligation to provide support for diversity) to diversity (see Cunningham, 2008a) by shaping and conveying a meta-narrative or story about diversity (i.e., the inclusion of women and racial minorities in leadership positions is an organizational mandate) in their athletic departments (see Chrobot-Mason et al., 2013).

These ADs' attitudes and behaviors regarding racial and gender diversity in leadership positions created a story for others in the athletic department to follow. They embraced aspects of both the "direct and control" and "cultivate and encourage" approaches in leading diversity efforts in their respective athletic departments. As mentioned earlier, Chrobot-Mason et al. (2013) described the direct and control approach as one where leaders establish explicit policies or mandates related to diversity. The African American male ADs' insistence and, essentially, requirement that women and/or racial minority candidates be included in the hiring pools for many of the leadership positions, as well as be given strong consideration for these positions during the hiring process, is an example of this approach we observed in this study. There were several examples across both organizations where these leaders were adamant about filling positions with women and/or racial minorities, even if/when doing so might have gone against conventional wisdom or raised legal and ethical questions. The example of the AD in athletic department 2 hiring the African American male in the assistant AD role who did not work out is a case in point. In taking a calculated risk in hiring a candidate he had personal doubts about, and who ended up not working out, perhaps this $\mathrm{AD}$ shared the mindset of former legendary Georgetown University men's basketball coach, John Thompson. As a panelist on the ESPN townhall meeting on race and sports in the late 1990s, Thompson expressed that Black candidates, like their White counterparts, should have the opportunity to be hired and given the chance to "fail" in head coaching and other leadership positions in college sport (see The White House, Office of the Press Secretary, 1998; Singer, Harrison, \& Bukstein, 2010).

In regard to the cultivate and encourage approach, Chrobot-Mason and colleagues suggested that leaders who embrace this approach focus on creating climates that encourage positive interactions between people and foster inclusive organizational environments. Even though both leaders in our study clearly embraced an authoritative, affirmative, and definitive approach to fostering racial and gender diversity in leadership positions, they still sought to cultivate and encourage open and honest dialogue about diversity in the athletic department. They created organizational cultures of diversity (Doherty \& Chelladurai, 1999) where their followers were afforded opportunities to critically think about and openly discuss the topic of diversity within the department (e.g., AD in athletic department 1 made it a part of the evaluation process). The organizational analysis the leader in athletic department 1 invested in assisted in this process of cultivating 
and encouraging open lines of communication about matters of diversity. It allowed the leader and his followers to identify and begin working to break down silos within the athletic department, and set up and engage in formal, mandatory diversity training as a mechanism for helping to break down barriers between and among his followers.

Next, findings from our study speak to the crucial role that racial minorities can play in being role models and mentors to marginalized groups in sport organizations. Carbado and Gulati (2009) acknowledged the importance and benefits of racial minorities in corporate and organizational leadership positions because they could serve as role models for and provide mentoring to their juniorlevel racial minority associates. But, these scholars suggested most racial minorities who have risen to the top of the corporate ladder may not "lift as they climb" (i.e., provide role modeling and mentoring to other racial minorities in the organizations). Our research findings challenge this assertion by revealing that the African American male ADs in our study not only seemed to go out of their way to include racial and gender minority representation on their senior leadership teams or in major decision-making positions (e.g., head coaches), but they also viewed doing so as critical to facilitating the role modeling and mentorship process in the athletic department and beyond. The followers of the ADs in both athletic departments spoke very highly of these diverse leaders, and viewed each as role models and mentors who lead by example. Some of the followers, particularly in athletic department 1 , shared how they hoped to emulate what they were learning from their leader if and when presented with the opportunity to one day lead their own athletic department. Of particular interest was the position of one of the followers (i.e., African American male assistant AD) in athletic department 1 who was prepared to "walk behind him for 25 more years if it has to happen that way."

Our findings also revealed that in addition to his followers within athletic department 1, many of his African American colleagues and peers at other institutions benefited from this AD's mentorship and diversity outreach efforts (e.g., the Black AD gathering he hosts regularly). Livers and Cavers (2003) discussed how African American leaders' approaches to leadership might be distinctive from their White peers in certain areas such as feelings of responsibility for other African Americans within and outside their organizations. Indeed, our findings suggest such was the case with the $\mathrm{AD}$ in athletic department 1 and his peer in athletic department 2. Each leader demonstrated a robust commitment and felt responsibility to help and look after their fellow Africans Americans both within and outside of their athletic departments. In the case of the leader in athletic department 1 this was clearly evident in his practice of regularly hosting African American ADs/athletics administrators from other U.S. colleges and universities on his campus; his peer in athletic department 2 demonstrated this felt responsibility to look out for other African Americans in some of the hiring decisions he intentionally made.

Finally, this felt responsibility to help and look after other African Americans in the organization was also evident in how each $\mathrm{AD}$ viewed themselves as important role models for all the athletes in general, but the African American athletes in particular. As mentioned earlier, the leader in athletic department 1 viewed his AD role as an asset he could use to help "deal with some of the Black issues with some of our players" because these athletes look at him differently than 
they perhaps would a White AD. This was also the case with the AD in athletic department 2. The narrative of the African American football athlete in this department was a great example of the different kind of relationship African American athletes in the organization had with this leader, and how his position as the AD placed an inherent responsibility on him to be a role model and mentor to the athletes in his athletic department. This felt responsibility speaks directly to the point Livers and Caver (2003) made about African American leaders' seemingly distinctive approaches to dealing with diversity issues in their organizations.

Findings from this study also point to some important implications for policy and practice. Our findings suggest that in order to counter the homologous reproduction or the continued predominance of White males in leadership positions within college sport there is a need for college and university presidents and other leaders in higher education and college sport to create and/or adopt hiring policies and practices aimed at increasing the presence of leaders and decision makers from historically under-represented groups in their athletic departments who have a demonstrated commitment to diversity. This is one of the reasons that the BCA hiring report card was established back in 2004. That is, although the focus of this report card was on critically examining the processes that PWIHE engage in to hire head football coaches (see Singer et al., 2010), such an examination could also focus on other leadership positions in college sport, which is similar to what the NFL's Rooney Rule does. Despite criticism of the NFL's Rooney Rule and its limited utility in truly addressing the dearth of head football coaches and executives at the professional level, leaders in higher education and college sport might benefit from adopting some of the ideas from this policy.

In addition to creating and/adopting hiring policies and practices to address diversity issues in college sport leadership structures, there is also a need for athletic departments at PWIHE to create, sustain, and strengthen organizational cultures of diversity like the ones the African American male ADs in our study attempted to foster. One of the best ways to improve the culture of diversity in these athletic departments would be to constantly monitor and periodically engage in organizational assessments of these cultures. Doing so will likely involve a significant investment of time and financial resources, but if these leaders in these athletic departments are truly sincere about improving their organizational cultures they should be willing to commit the resources to that cause, like the African American AD in athletic department 1 did. Related to that point, in order to create and sustain a healthy climate or mood throughout the organization, leaders must commit to providing and mandating various forms of diversity training and professional development opportunities for employees and other stakeholders of these athletic departments.

In terms of future research directions, there are several possibilities and avenues to explore going forward. First and foremost, scholars should explore the unique set of dynamics nontraditional leaders such as African American male ADs might face in traditionally-White male-dominated sport organizations such as college and university athletic departments. Livers and Caver (2003) referred to the extra burdens and potentially negative consequences African American leaders face and the state of unease it could cause as miasma. In discussing the impact miasma could have on how African American leaders perceive and experience the workplace differently from their mostly White colleagues, these scholars focused 
on identity, responsibility, race and gender, networking, mentoring, and being politically savvy as six distinctive areas. Findings from our study provide support for the areas of felt responsibility and a heighted emphasis on race and gender being potentially distinctive areas of focus for African American leaders. However, future research should further explore these and the other areas discussed by Livers and Caver.

Given that perceptions of identity could be one significant difference for African American and other nontraditional leaders (e.g., women, sexual minorities, religious minorities, and people with disabilities) in traditionally-White maledominated sport organizations, future research should specifically examine this particular area. Slay (2003) argued the social identity literature enables the examination of leadership as a function of in-group/out-group membership, and allows for the analysis of African Americans as members of multiple constituent groups (i.e., work groups and political coalitions, African American ethnicity). Because we did not focus explicitly on the salience of identity for the African American male ADs in our study, future research could focus on the salience of leaders' identities (racial and otherwise) and the impact it has on their mindsets and leadership approaches to diversity in sport organizations. Both qualitative (see, for example, Singer \& Cunningham, 2012) and quantitative (see, for example, Cunningham, 2008a) studies could focus specifically on leaders from various distinctive social groups (e.g., African American women, White men) and how these individuals' social identities might impact their mindsets and approaches to diversity in their sport organizations. Moreover, research could indeed compare and contrast the differences between and among leaders from different groups in efforts to understand how identity might impact their commitment to diversity.

In conclusion, our research here was not concerned with a direct comparison between African American leaders and their White counterparts, and the distinctive differences that could be present as a result of miasma. Instead, it was delimited by a focus on understanding and comparing how two African American male leaders thought about and approached diversity in their respective athletic departments at PWIHE. While we agree that going forward scholars might consider doing comparative studies between traditional leaders (i.e., White, protestant, ablebodied, heterosexual males) and African American and other nontraditional leaders in sport organizations, it is our belief that an examination of the latter group was and is a necessary and important end as well. In other words, there is not a need to view traditional leaders as the optimal status criterion and always use them as a point of comparison to examine the mindsets and behaviors of nontraditional leaders in intercollegiate athletics and other sport organizational contexts.

\section{Note}

1. The terms African American and Black are used interchangeably throughout this paper.

\section{Acknowledgments}

The authors would like to acknowledge and thank the National Collegiate Athletic Association (NCAA) for providing grant funding that helped them complete this research study. 


\section{References}

Anderson, D. (1993). Cultural diversity on campus: A look at intercollegiate football coaches. Journal of Sport and Social Issues, 17(1), 61-66. doi:10.1177/ 019372359301700108

Bell, D. (1992). Faces at the bottom of the well: The permanence of racism. New York, NY: Basic Books.

Bimper, A.Y., Jr., \& Harrison, L., Jr. (2017). Are we committed to issues of race? Institutional integrity across intercollegiate athletics. International Review for the Sociology of Sport, 52(6), 675-692. doi:10.1177/1012690215616270

Brooks, D., \& Althouse, R. (2000). African American head coaches and administrators: Progress but ... ? In D. Brooks \& R. Althouse (Eds.), Racism in college athletics: The African American athlete's experience (2nd ed., pp. 85-118). Morgantown, WV: Fitness Information Technology.

Carbado, D.W., \& Gulati, M. (2009). Race to the top of the corporate ladder: What minorities do when they get there? Research in Law and Economics: A Journal of Policy, 24, 237-270.

Chemers, M.M., \& Murphy, S.E. (1995). Leadership and diversity in groups and organizations. In M.M. Chemers, S. Oskamp, \& M.A. Costanzo (Eds.), Diversity in organizations: New perspectives for a changing workplace (pp. 157-188). Thousand Oaks, CA: Sage.

Chin, J.L. (2010). Introduction to the special issue on diversity and leadership. American Psychologists, 65(3), 150-156. doi:10.1037/a0018716

Chrobot-Mason, D., Ruderman, M.N., \& Nishii, L.H. (2013). Leadership in a diverse workplace. In Q.M. Roberson (Ed.), The oxford handbook of diversity and work (pp. 315-340). New York, NY: Oxford University Press.

Cokley, K., Dreher, D.F., \& Stockdale, M.S. (2004). Toward the inclusiveness and career success of African Americans in the workplace. In M.S. Stockdale \& F.J. Crosby (Eds.), (pp. 168-190) The psychology and management of workplace diversity. Malden, MA: Blackwell Publishing.

Corbett, D.R., \& Tabron, M.J. (2007). An examination of athletic directors' perception of barriers to employment opportunities. In D. Brooks \& R. Althouse (Eds.), Diversity and social justice in college sports: Sport management and the student athlete (pp. 159-178). Morgantown, WV: Fitness Information Technology.

Cox, T. (1993). Cultural diversity in organizations: Theory, research \& practice. San Francisco, CA: Berrett-Koehler.

Creswell, J.W. (2007). Qualitative inquiry \& research design: Choosing among five approaches (2nd ed.). Thousand Oaks, CA: Sage.

Cunningham, G.B. (2008a). Commitment to diversity and its influence on athletic department outcomes. Journal of Intercollegiate Sport, 1, 176-201. doi:10.1123/jis.1.2.176

Cunningham, G.B. (2008b). Understanding diversity in intercollegiate athletics. Journal for the Study of Sports and Athletes in Education, 2, 321-338. doi:10.1179/ssa.2008. 2.3.321

Cunningham, G.B. (2009). Understanding the diversity-related change process: A field study. Journal of Sport Management, 23, 407-428. doi:10.1123/jsm.23.4.407

Cunningham, G.B. (2012). Diversity training in intercollegiate athletics. Journal of Sport Management, 26, 391-403.

Cunningham, G.B. (2015). Diversity and inclusion in sport organizations (3rd ed.). Scottsdale, AZ: Holcomb Hathaway.

Cunningham, G.B., \& Sagas, M. (2005). Access discrimination in intercollegiate athletics. Journal of Sport \& Social Issues, 29(2), 148-163. doi:10.1177/0193723504271706 
Cunningham, G.B., \& Sartore, M.L. (2010). Championing diversity: The influence of personal and organizational antecedents. Journal of Applied Social Psychology, 40(4), 788-810. doi:10.1111/j.1559-1816.2010.00598.x

Cunningham, G.B., \& Singer, J.N. (2011). The primacy of race: Department diversity and its influence on the attraction of a diverse fan base and revenues generated. International Journal of Sport Management, 12, 176-190.

DeSensi, J.T. (1995). Understanding multiculturalism and valuing diversity: A theoretical perspective. Quest, 47, 34-43. doi:10.1080/00336297.1995.10484143

DiTomaso, N., Hooijberg, R. (1996). Diversity and the demands of leadership. Leadership Quarterly, 7(2), 163-187. doi:10.1016/S1048-9843(96)90039-9

Doherty, A.J., \& Chelladurai, P. (1999). Managing cultural diversity in sport organizations: A theoretical perspective. Journal of Sport Management, 13, 280-297. doi:10.1123/ jsm.13.4.280

Eagly, A.H., \& Chin, J.L. (2010). Diversity and leadership in a changing world. American Psychologist, 65(3), 216-224. PubMed ID: 20350020 doi:10.1037/a0018957

Embrick, D.G. (2011). The diversity ideology in the business world: A new oppression for a new age. Critical Sociology, 37(5), 541-556. doi:10.1177/0896920510380076

Feagin, J. (2006). Systemic racism: A theory of oppression. New York, NY: Routledge.

Fink, J.S., \& Pastore, D.L. (1999). Diversity in sport? Utilizing the business literature to devise a comprehensive framework of diversity initiatives. Quest, 51, 310-327. doi:10. 1080/00336297.1999.10491688

Flyvbjerg, B. (2006). Five misunderstandings about case-study research. Qualitative Inquiry, 12(2), 219-245. doi:10.1177/1077800405284363

Gilbert, J.A., \& Ivancevich, J.M. (2000). Valuing diversity: A tale of two organizations. Academy of Management Executive, 14(1), 93-105.

Harrison, D.A., Kravitz, D.A., Mayer, D.M., Leslie, L.M., \& Lev-Arey, D. (2006). Understanding attitudes toward affirmative action programs in employment: Summary and meta-analysis of 35 years of research. Journal of Applied Psychology, 91(5), 10131036. PubMed ID: 16953765 doi:10.1037/0021-9010.91.5.1013

Kersten, A. (2000). Diversity management: Dialogue, dialectics and diversion. Journal of Organizational Change Management, 13(3), 235-248. doi:10.1108/095348100103 30887

Lapchick, R. (2018, March). College sports racial and gender report card. ESPN. Retrieved from http://www.espn.com/mens-college-basketball/story/_id/22602600/the-ncaacontinues-struggle-2017-racial-gender-report-card

Livers, A.B., \& Caver, K.A. (2003). Leading in black and white: Working across the racial divide in corporate America. San Francisco, CA: Jossey-Bass.

McCarty Kilian, C., Hukai, D., \& McCarty, C.E. (2005). Building diversity in the pipeline to corporate leadership. Journal of Management Development, 24(2), 155-168. doi:10. 1108/02621710510579518

Morrison, A.M. (1992). The new leaders: Guidelines on leadership diversity in America. San Francisco, CA: Jossey-Bass.

National Collegiate Athletic Association. (n.d.). Sport sponsorship, participation, and demographics. Retrieved from http://web1.ncaa.org/rgdSearch/exec/instSearch

Rich, K.A., \& Giles, A.R. (2015). Managing diversity to provide culturally safe sport programming: A case study of the Canadian Red Cross's swim program. Journal of Sport Management, 29(3), 305-317.

Sage, G.H. (2007). Introduction. In D. Brooks \& R. Althouse (Eds.), Diversity and social justice in college sports: Sport management and the student-athlete (pp. 1-17). Morgantown, WV: Fitness Information Technology.

Schwandt, T.A. (2007). Qualitative inquiry: A dictionary of terms. Thousand Oaks, CA: Sage. 
Singer, J.N., \& Cunningham, G.B. (2012). A case study of the diversity culture of an American university athletic department: Implications for educational stakeholders. Sport, Education \& Society, 17, 647-669. doi:10.1080/13573322.2011.552572

Singer, J.N., Harrison, C.K., \& Bukstein, S.J. (2010). A critical race analysis of the hiring process for head coaches in NCAA college football. Journal of Intercollegiate Sport, 3(2), 270-296. doi:10.1123/jis.3.2.270

Slay, H.S. (2003). Spanning two worlds: Social identity and emergent African-American leaders. Journal of Leadership and Organizational Studies, 9(4), 56-66. doi:10.1177/ 107179190300900405

Spaaij, R., Farquharson, K., Magee, J., Jeanes, R., Lusher, D., \& Gorman, S. (2014). A fair game for all? How community sports clubs in Australia deal with diversity. Journal of Sport and Social Issues, 38(4), 346-365. doi:10.1177/0193723513515888

Spracklen, K., Hylton, K., \& Long, J. (2006). Managing and monitoring diversity and equality in UK sport: An evaluation of the sporting equals racial equality standard and its impact on organizational change. Journal of Sport and Social Issues, 30(3), 289305.

Stake, R.E. (2005). Qualitative case studies. In N.K. Denzin \& Y.S. Lincoln (Eds.), The sage handbook of qualitative research (3rd ed., pp. 443-466), Thousand Oaks, CA: Sage.

The White House, Office of the Press Secretary. (1988, April 14). Remarks by the president in ESPN live: A conversation with the president, sport and race: running in place? Retrieved from https://clintonwhitehouse4.archives.gov/WH/New/html/199804158261.htmlh

Thomas, D.R. (2006). A general inductive approach for analyzing qualitative evaluation data. American Journal of Evaluation, 27(2), 237-246. doi:10.1177/1098214005283748

Thomas, K.M., \& Plaut, V.C. (2008). The many faces of diversity resistance in the workplace. In K.M. Thomas (Ed.), Diversity resistance in organizations (pp. 122), New York, NY: Lawrence Erlbaum Associates.

Thomas, R.R. (1990). From affirmative action to affirming diversity. Harvard Business Review, 68(2), 107-117. PubMed ID: 10106515

Tsui, A.S., \& Gutek, B.A. (1999). Demographic differences in organizations. New York: Lexington Books.

Wyatt, M., \& Silvester, J. (2015). Reflections on the labyrinth: Investigating black and minority ethnic leaders' career experiences. Human Relations, 68(8), 1243-1269. doi: $10.1177 / 0018726714550890$

Zanoni, P., Janssens, M., Benschop, Y., \& Nkomo, S. (2010). Unpacking diversity, grasping inequality: Rethinking difference through critical perspectives. Organization, 17(1), 9-29. doi:10.1177/1350508409350344 